\title{
Metallurgy and metaterials Pelletizing furnace refractory lining life cycle extension by applying thermography analysis and direct refractory injection \\ http://dx.doi.org/10.1590/0370-44672017710163
}

Fernando Luiz Câmara Campos Junior http://orcid.org/0000-0002-8131-9624

Mestrando

Universidade Federal de Ouro Preto - UFOP REDEMAT

Ouro Preto - Minas Gerais - Brasil

fluiz.junior@hotmail.com

\section{Sebastiana Luiza Bragança Lana \\ Professor-Titular \\ Universidade do Estado de Minas Gerais - UFMG \\ Professor do Curso de Pós Graduação na \\ REDEMAT \\ Belo Horizonte - Minas Gerais - Brasil \\ sebastiana.lana@gmail.com}

\section{Paulo Santos Assis}

Professor-Titular

Universidade Federal de Ouro Preto - UFOP

Escola de Minas

Departamento de Engenharia Metalúrgica

Ouro Preto - Minas Gerais - Brasil

assis.ufop@gmail.com

\section{Benito Barbabela e Silva}

Engenheiro de operação e processos na VALE

Nova Lima - Minas Gerais - Brasil

benito.silva@vale.com

\section{Introduction}

The production of iron ore and steel has significantly expanded in recent years, particularly in developing countries such as China and India, resulting in a large increase in the demand for iron ore. The quality of iron ore deposits has been deteriorating worldwide and the existing mines are facing increasing difficulty in producing high grade ores (NOMURA, YAMAMOTO, FUJII, \& TAKIGUCHI, 2015).

Since 1950 , it has been possible to observe that there is an increasing occurrence of low grade material. Such material requires more complex beneficiation steps to concentrate and so, at the same

\begin{abstract}
The induration furnace is one of the most important devices in the pellet production system. It is responsible for ensuring the quality of pellets produced, since a high level of thermal energy is necessary to reach the physical properties needed. Therefore, the refractory lining performance is important to guarantee the quality of pellets and to avoid thermal losses. Minor failures in the refractory lining may result in serious damage, if it not previously identified and repaired. This article was written to explain a preventive technique to identify and repair such minor issues with the refractory lining before escalation. The use of this technique in the proper frequency may result in furnace life cycle extension.
\end{abstract}

Keywords: pelletizing; refractory lining; thermography. time, more ultrafine iron ore (pellet feed) needs to be processed, mainly in the new projects (MOURÃO, 2008).

The pelletizing process was developed in 1912 by A. G Anderson and C.A Brackelsberg (CAPPEL \& LUNGEN, 1999) and consists in agglomerating the ultrafine iron ore, bellow $0.045 \mathrm{~mm}$, in order to achieve a product with suitable size distribution to be used directly in reduction reactors.

The processed material of a pelletizing plant is called pellets, and is made of ultrafine iron ore agglomerated by using discs or drums forming green balls (YAMAGUCHI, FUJII, YAMAMOTO,
\& NOMURA, 2010).

The iron ore pellet quality is obtained when mechanical resistance is added to the agglomerates. This property is obtained by the thermal treatment of pellets in the Travelling Grate furnace (ATHAYDE, TAVARES, NUNES, \& FONSECA, 2004).

Travelling Grate furnaces are thermal devices based on intense heat exchange by convection. A set of burners are used to increase the temperature of air coming from the environment and from the heat recovery system. Heated air is pushed through the green pellet bed to perform the burning stage. In the 
cooling zone, cool air is pushed through the burnt pellets and the resultant hot air is conducted back to the burning stage for heat recovery.

The furnace is a metal structure coated with refractory lining, designed to endure heat to the order of $1350^{\circ} \mathrm{C}$.

The downward gas flow at the temperature of about $1350^{\circ} \mathrm{C}$ raises the pellet temperature levels. As a thermal source, considering the travelling grate technology, burners are positioned laterally in the firing zone using natural gas or oil as fuel. The burners use preheated air at the temperature of about $1000^{\circ} \mathrm{C}$ to perform the combustion. The recovered duct positioned above the firing zone

\section{Materials and methods}

Infrared thermography is a preventive and predictive maintenance tool, figuring as a promising tool for fast and reliable condition monitoring, among other non-destructive inspection and test- guarantees the homogeneous flow of preheated air to all burners.

All properties of the agglomerate are obtained during firing. This step is therefore crucial to ensure the quality of the produced pellets (MEYER, 1980).

The heat recovery system depends a great deal on the refractory lining performance, as the insulation provided is responsible to minimize the heat exchange with the atmosphere. Therefore, in case of refractory damage, the insulation fails, resulting in energy consumption increase and a possible escalation of structural problems.

Minor cracks are capable of leading to heavy structural problems in the refractory lining, and if such problems are not identified in the early stage, they can result in structural collapse of the furnace, causing furnace life cycle reduction.

The refractory lining condition is the main indicator to determine the exact time and duration of major shutdowns. Normally, such interventions take 20 to 30 days to complete.

Refractory lining condition monitoring is crucial to avoid premature problems as well as structural collapse. Moreover, the application of correct measures to effectively avoid such problems might lead to a furnace life cycle extension. ing techniques available (MAYERKAR, KOTMIRE, WAGH, \& SHINDE, 2016). By observing the heat patterns in operational system components, cracks can be located and their seriousness evaluated.
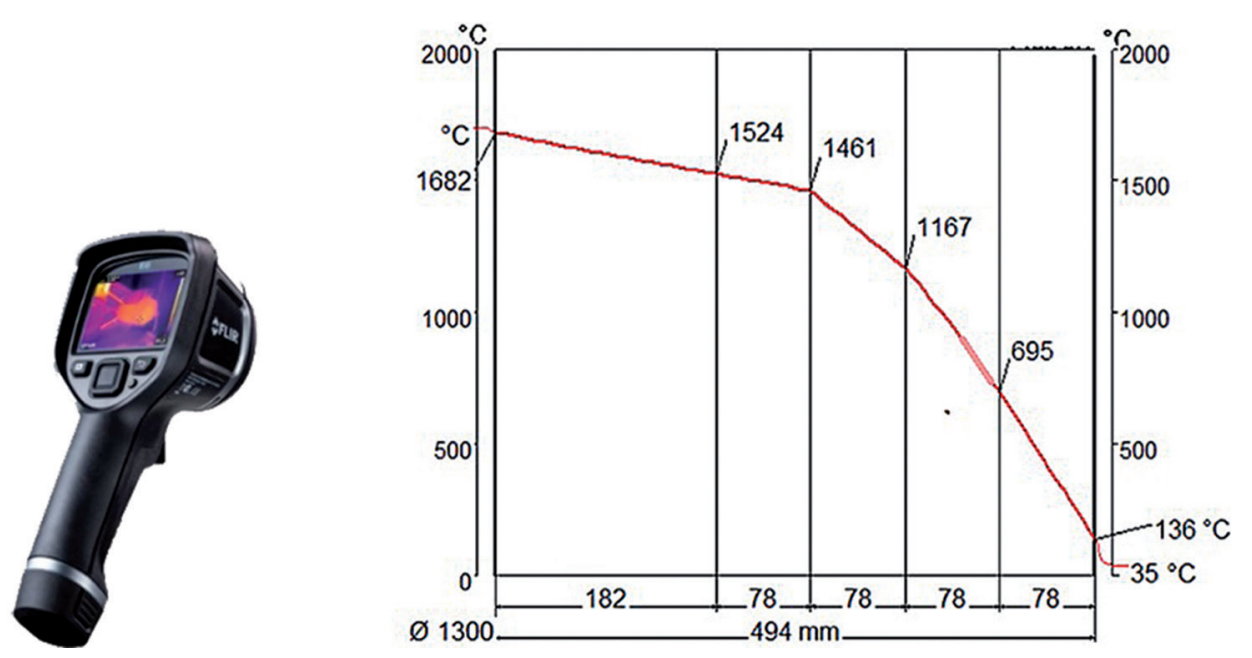

The measurement program was based upon a map of critical regions pointed out by the maintenance program and process staff. The criticality

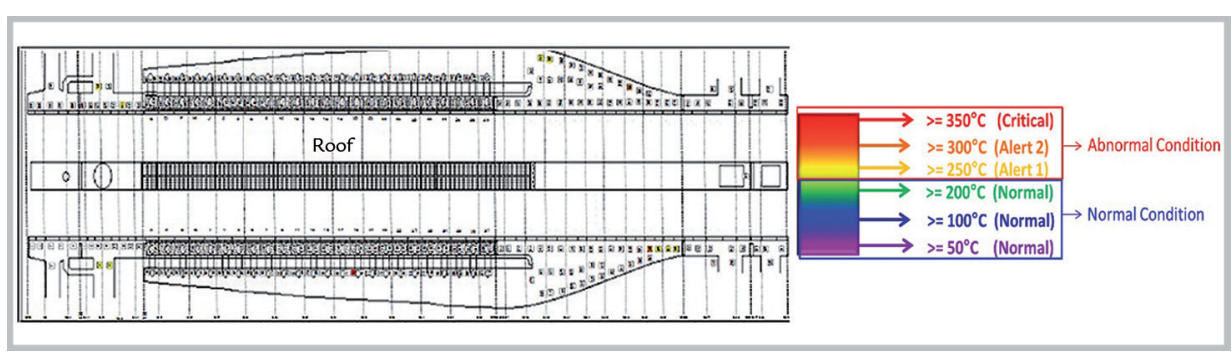

The thermographic measurement was done 6 times in a period of twelve months to follow the evolution of the inner surface temperature level.

To avoid the increase of inner surface temperature, refractory mass was injected in the critical points, identified with thermography.

To inject the refractory mass, a very simple manual device was used. The injectable mass was selected with the same chemical quality of the refractory lining.

For the mass injection, a hole is
In this study, a thermographic camera FLIR series E30 was used to obtain detailed information about the furnace's inner surface temperature. Figure 1 shows the thermographic camera used.
Figure 1

Thermographic camera series E30 of FLIR and Typical thermal profile possible to find in across the burner chamber refractory of a pelletizing furnace.

of the points were ranked according to Figure 2.
Figure 2

Thermography mapping and criticality classification.

bored through the furnace structure in the area where hot spots were detected, using an industrial drilling machine and a $12 \mathrm{~mm}$ drill bit. The refractory mass is then injected through the bore by pressure. 


\section{Results and discussions}

According to the procedure, Figure 3 presents the results of the last 4 mea-

Figure 3

Summary results of the recent inspections.

By examining the results, it is possible to verify that the hot spots were located mainly in the corners of the structure, indicating that most

Figure 4 Thermography made in the primary cooling.

Figure 5

Thermography image at the firing zone. surements.

results indicate degradation of the re-

Therefore, the thermography fractory lining condition.

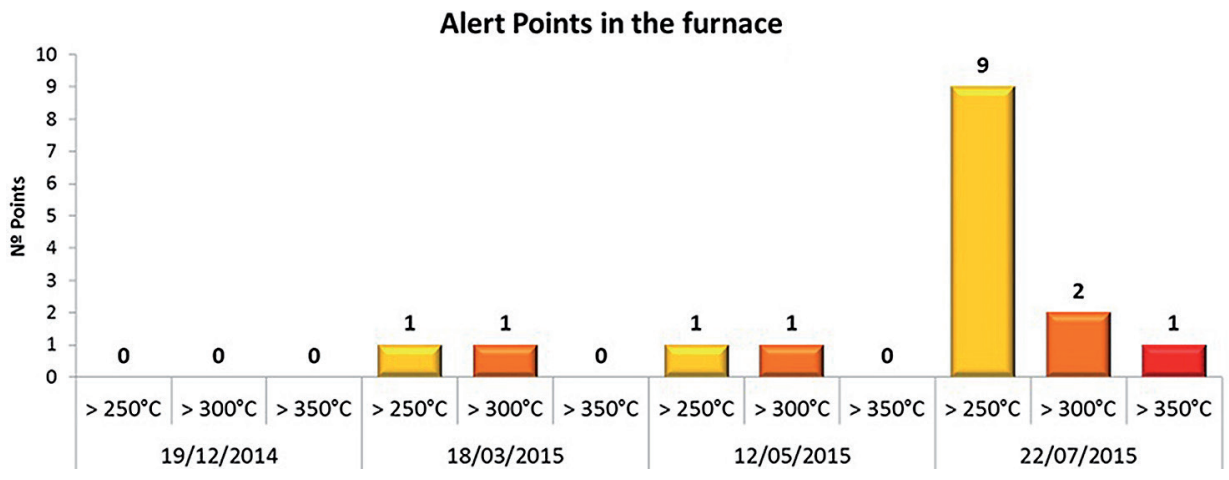

failures in the refractory lining start at these regions are always included in its borders. the thermography path. Figures 4 and This trend must be considered in 5 illustrate that situation. the inspection planning, ensuring that
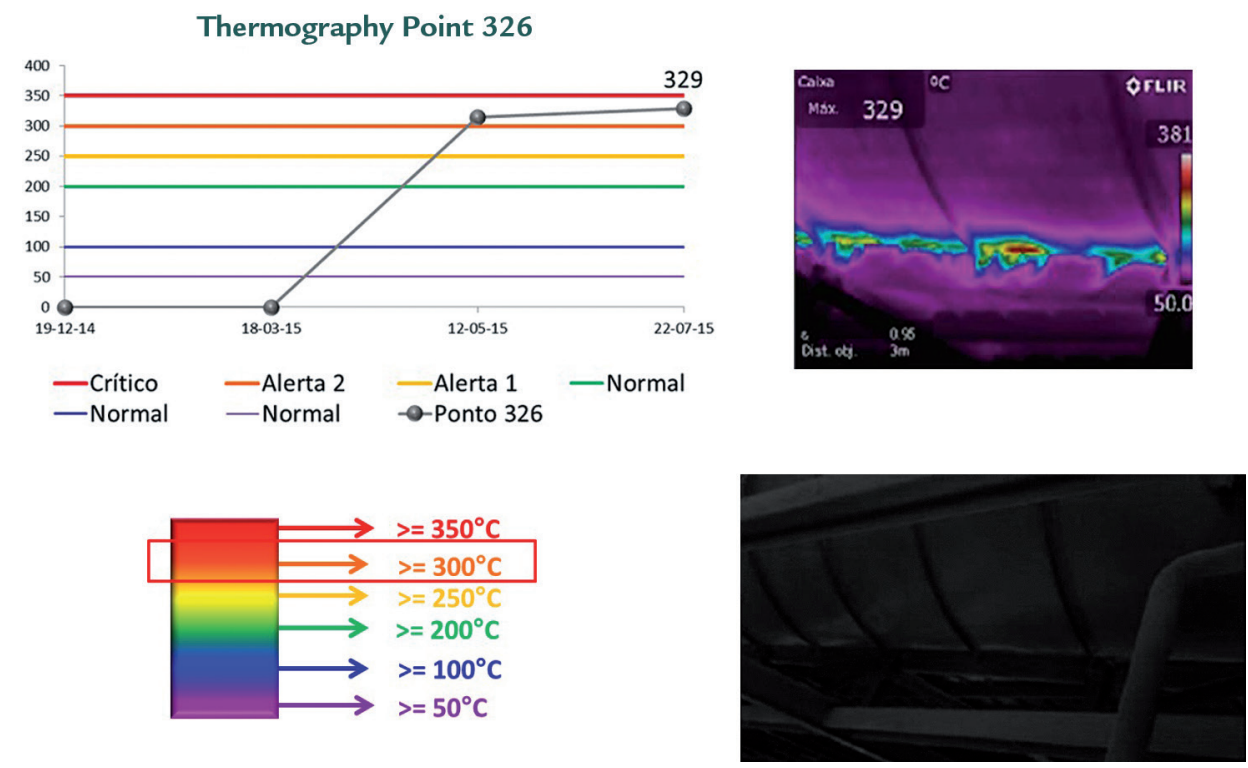

Thermography Point 74
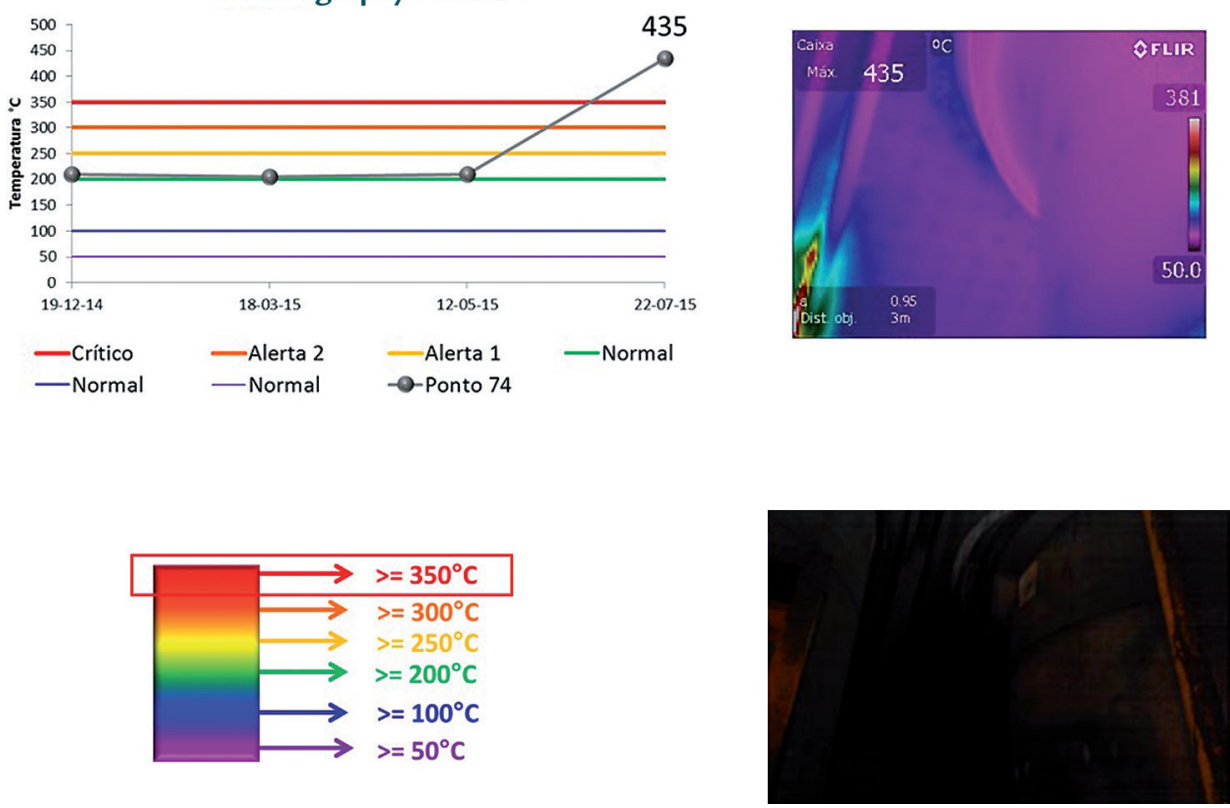
In summary, the hot spots identified are presented in the scheme in the Figure 6:

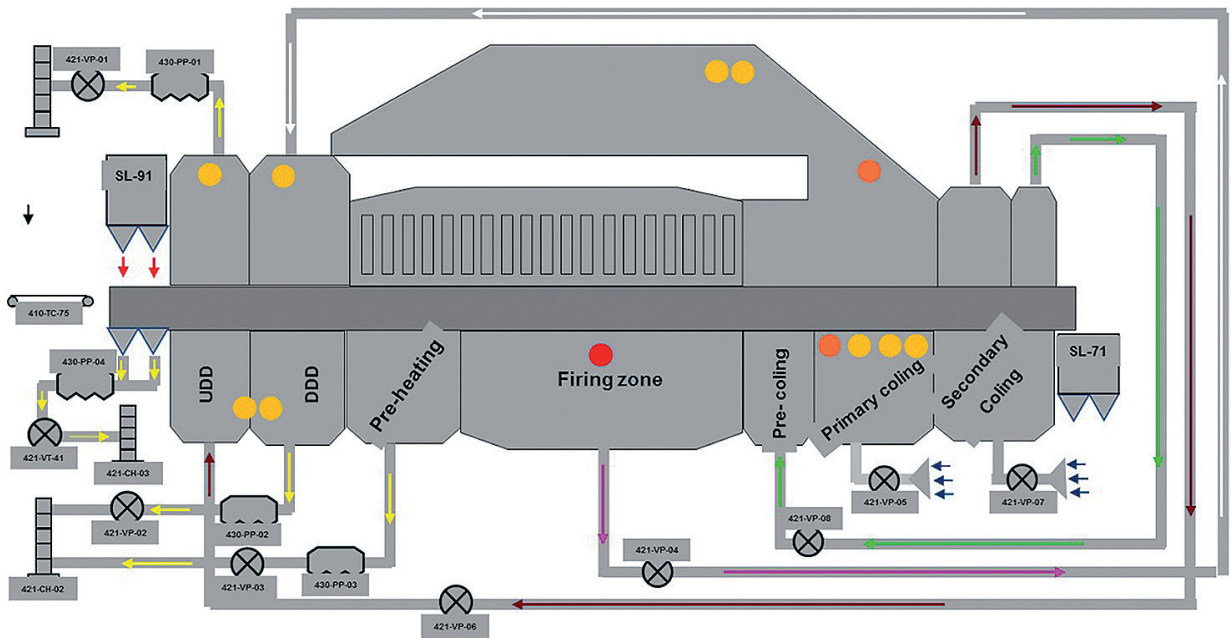

In an attempt to understand the reasons why hot spots are happening, besides cracks in the refractory borders, it was possible to conclude that the dust

accumulated on the inner furnace surface prevents the heat exchange with the atmosphere, reflecting the head back to the refractory fastening and lining.

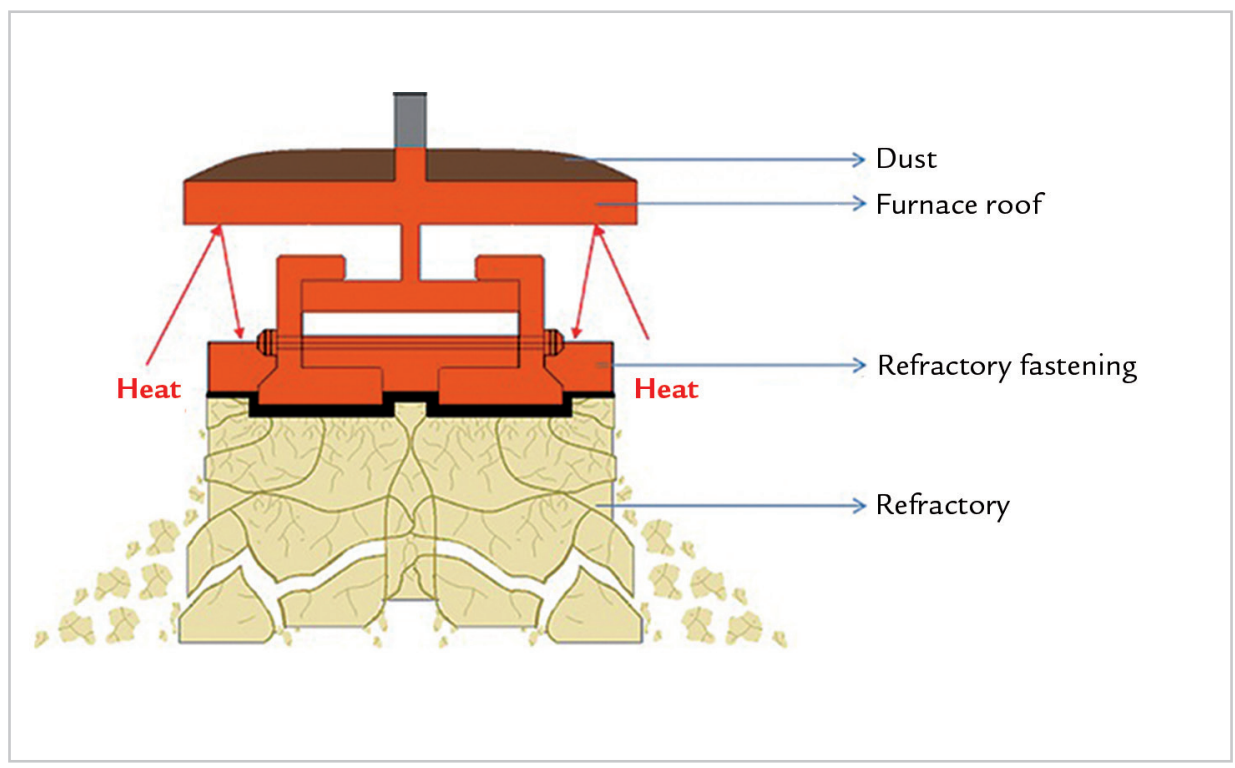

Therefore, the cleaning of the surface structure is a factor as important as the refractory wear out. Therefore, a periodic cleaning must be done to avoid crack formation/evolution in the refractory lining.
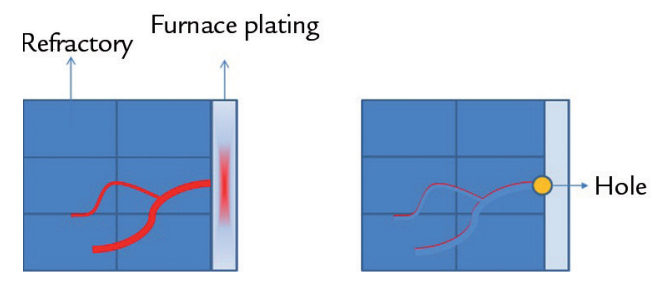

To repair the refractory lining issues, a mass injection was made in the hot spot areas to block the evolution of cracks and to reduce the temperature in these regions identified in the thermography.

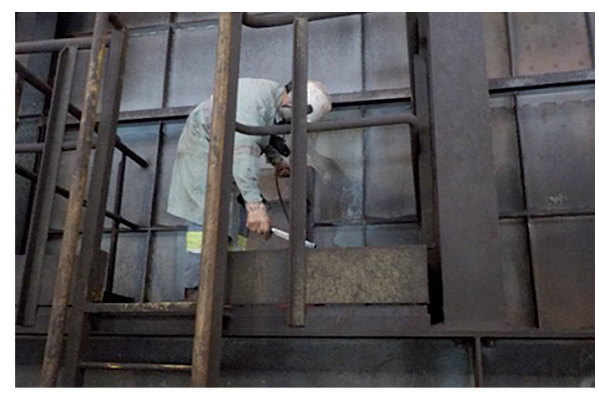

A double-check was conducted to verify the effectiveness of the actions taken. According to the results, all 12 hot spots identified were recovered
Figure 6

Hot spots in the furnace.

Figure 7 shows the scheme of the cracks' evolution due to the prevention of heat transfer between the structure surface and atmosphere air.

Figure 7

Cracks evolution due to dust accumulation on the structure surface.

The main idea of the mass injection is to fill the cracks with refractory mass, taking advantage of the process temperature to make quick solidification, thus blocking the crack evolution as per the scheme in the Figure 8.

Figure 8

Mass Injection.

and the temperatures returned to the normal condition (Figure 9). 
Figure 9

Before/after in the primary cooling and firing zone.

Thermography was used as a tool of great effectiveness to identify the hot spots on the furnace structure surface. Moreover, Thermography makes the preventive inspections easier because some areas in the furnace are difficult to access.

Thermography also helped to make these inspections frequently, as the equipment is very easy to operate and the

Figure 10

Furnace life cycle forecast.

From historic data, normally the furnace campaign is around 4.3 years. Using the preventive methods in this

\section{Conclusions}

Thermography is a very versatile method and was used to identify the hot spots showing practicality and assertiveness.

The mass injection method is a very simple technique and perfectly performed the task of filling cracks, avoiding crack propagation and further (a)

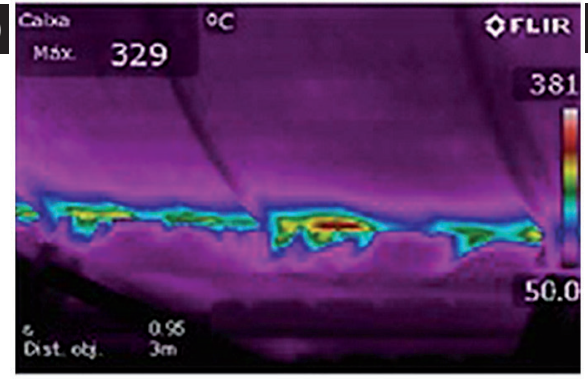

(a) Primary cooling - before

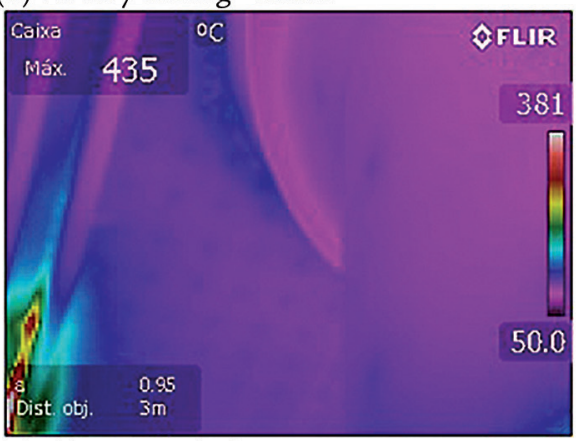

(a) Firing zone - before

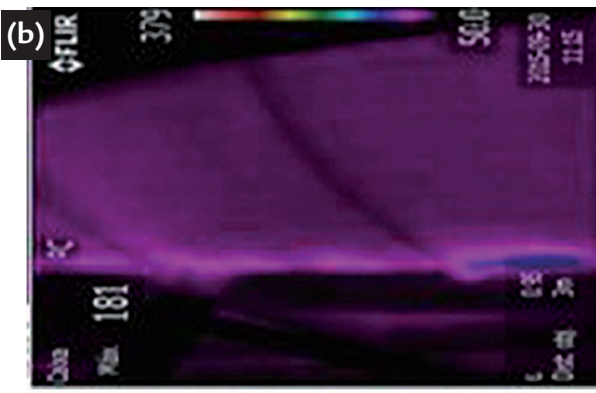

(b) Primary cooling - after

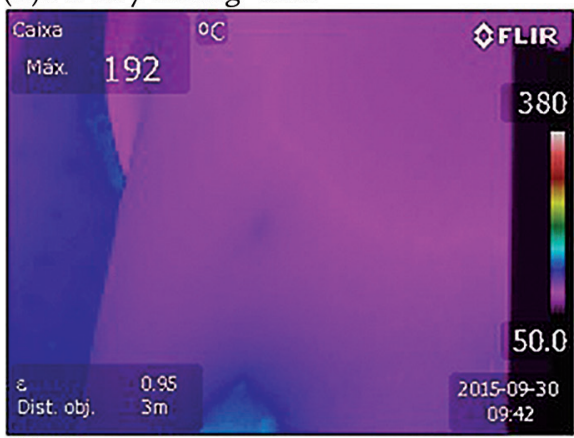

(b) Firing zone - after

information can be easily manipulated to identify the points that needing attention.

When using Thermography results, combined with the mass injection technique developed, it is possible to avoid the refractory lining crack evolution, as well as to avoid the refractory and the furnace structure collapse.

Therefore, Thermography used to-

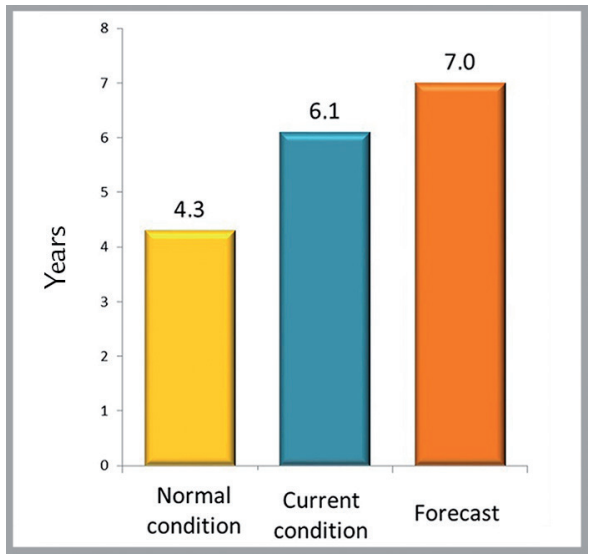

document, it is probably possible to reach more than 7 years of life. This result has a very high impact in the total

issues with the refractory lining and furnace structure.

The cleaning of the roof is very important to avoid crack formation in the refractory lining and must be done with proper frequency.

Therefore, the utilization of the 2 techniques combined results in a power- gether with the Mass Injection technique demonstrated our procedure to be an effective preventive tool. As long as it is performed with proper frequency, it can be used to identify and repair refractory lining issues, thus increasing the life cycle of the furnace.

The application of this method yields the results shown in the Figure 10:

operational cost, energy consumption and pellet quality.

ful preventive tool, allowing fast, easy and assertive execution.

This technique used in the proper frequency can avoid crack propagation, preventing premature reduction of the life cycle, and if used as a preventive action, may result in the life cycle increase of the furnace. 


\section{References}

ATHAYDE, M., TAVARES, R., NUNES, S., FONSECA, M. Avaliação da distribuição de gases em fornos de pelotização da Samarco Mineração através de CFD e validação experimental. Tecnologia em Metalurgia, Materiais e Mineração, v.11, n.4, p.340 - 345, 2004.

CAPPEL, F., LUNGEN, H. Historical review of developments in sintering and pelletizing techniques. In: SEMINAR ON SINTER AND PELLETS. Bruxelas: IISI - International Iron and Steel Institute, 1999. p. 12 - 31.

MAYERKAR, P., KOTMIRE, N. J., WAGH, M., SHINDE, N. Review on thermographic analysis of PV panels/system using the infrared thermal cameras. International Journal of Scientific Engineering and Applied Science, v.2, n.4, p.135 - 139, 2016.

MEYER, K. Pelletizing of iron ores. Berlin, Düsseldorf: Heidelberg Springer-Verlarg, 1980.

MOURÃO, J. M. Estudo prospectivo do setor siderúrgico: NT minério de ferro e pelotas, situação atual e tendências 2025. Brasília: Centro de Gestão e Estudos Estratégicos, 2008.

NOMURA, T., YAMAMOTO, N., FUJII, T., TAKIGUCHI, Y. Beneficiation plants and pelletizing plants for utilizing low grade iron ore. Kobelco Technology Review, p. $8-15,2015$.

YAMAGUCHI, S., FUJII, T., YAMAMOTO, N., NOMURA, T. (2010, December). KOBELCO Pelletizing Process. Kobelco Technology Review, p. 58 - 68, 2010.

Received: 14 November 2017 - Accepted: 26 February 2018. 